\title{
Mixed Convection Heat Transfer in a Square Lid-Driven Cavity Filled with $\mathrm{Al}_{2} \mathrm{O}_{3}$-Water Nanofluid
}

\author{
Yazan Taamneh ${ }^{1, *}$ - Kahled Bataineh ${ }^{2}$ \\ 1 Jordan University of Science and Technology, Department of Aeronautical Engineering, Jordan \\ 2 Jordan University of Science and Technology, Department of Mechanical Engineering, Jordan
}

This work is focused on the steady laminar mixed convection flow in a lid-driven square cavity filled with $\mathrm{Al}_{2} \mathrm{O}_{3}$ water-nanofluid using computational fluid dynamics. The top lid of the cavity was kept at a higher temperature in comparison with the bottom wall and moving at a constant speed while the left and right walls were kept insulated. Simulations were performed using Fluent ver. 6.3 where the water based nanofluid was considered as a single phase. A parametric study was conducted, and the effects of the Richardson number $(0.1 \leq R i \leq 10)$, the volume fraction of the nanoparticle $(0 \leq \varphi \leq 0.04)$ on the fluid flow, and heat transfer inside the cavity were investigated. It was found that when $(1 \leq R i \leq 10)$ the average Nusselt number increases accordingly for the whole range of solid volume fraction of the nanofluid. The simulation results showed that the presence of nanoparticles in the base fluid increases the heat transfer rate. The variations of isotherm and streamline patterns inside the cavity with different volume fractions of nanoparticle and Richardson number were discussed and demonstrated.

Keywords: mixed convection, nanofluid, square cavity, CFD, lid-driven

Highlights

- The research focused on steady laminar mixed convection flow in a lid-driven cavity.

- $\quad$ The cavity was filled with $\mathrm{Al}_{2} \mathrm{O}_{3}$ water nanofluid.

- $\quad$ The effect of the volume fraction of the nanoparticles was investigated.

- The heat transfer rate was enhanced by increasing the solid volume fraction.

\section{INTRODUCTION}

The combination of the mixed convection flow and the heat transfer analysis in a lid-driven cavity has recently received significant attention by many researchers due to its significance in many practical engineering and industrial applications. The flow and heat transfer due to mixed (free and forced) convection are a combination of the flow induced by the shear forces resulting from the motion of the upper lid and the bouncy forces due to the temperature gradient. The practical flow situation is considered to be a complex phenomenon because of the interaction and coupling of these effects. In addition, there are various combinations of imposed temperature gradients and many cavity configurations of a liddriven cavity encountered in several engineering applications. Cha and Jaluria [1] studied in detail the impact of bounciness, velocities, and temperature fields on the heat transfer enhancement inside storage regions. Ghia et al. [2] investigated the driven flow in a square cavity at a high-Re fine-mesh flow.

The solid particles are used as an additive suspended in the base fluid to enhance the heat transfer in a variety of applications, such as microelectromechanical systems (MEMS), oil extraction and automobiles [3], electronic cooling, thermohydraulics of nuclear reactors, and solar ponds [4].
Kumar et al. [5] developed bactericidal coatings by using synthesized metal-nanoparticle (MNP)embedded paint. They showed that the surfaces coated with silver-nanoparticle paint have excellent antimicrobial properties. Choi [6] proposed a new class of engineering fluids with superior nanofluid thermal conductivity by adding nanoparticles. Vajjha and Das [7] studied how nanofluid thermophysical properties varied with temperature and concentration. They analysed their effects on the heat transfer coefficient, the pumping power, and friction factor. They asserted that enhancing the heat transfer rate by adding solid materials reduces operation costs. Numerous experimental and numerical investigations have been conducted on the heat transfer enhancement using nanofluid. Kaheld and Vafai [8] investigated the heat transfer enhancement inside channels by commanding thermal dispersion influences. They found that the distribution of dispersive elements increases the heat transfer. Torrance et al. [9] examined early the fluid motion inside different aspect ratio cavities generated by a moving wall under natural and mixed convection. They revealed that when Grashof number increases especially in cavities with high aspect ratio, the buoyancy effect would be significant. The buoyancydriven heat transfer enhancement of nanofluid in a two-dimensional enclosure has been analysed by Khanafer et al. [10]. Furthermore, various studies of 
the thermophysical properties of nanofluid and energy transport were carried out. Jung et al. [11], Kang et al. [12], and Lee et al. [13] measured the effective thermal conductivity for different types of nanofluid using the transient hot wire method. Wang and Mujumdar [14] outlined the recent research on fluid flow and heat transfer characteristics of nanofluid in forced and free convection flows.

Pak and Cho [15] showed experimentally that the convection heat transfer coefficient for $\mathrm{Al}_{2} \mathrm{O}_{3}$-water and $\mathrm{TiO}_{2}$-water nanofluid was enhanced by increasing the volume fraction as well as the average velocity. Xuan and Li [16] and [17] conducted an experimental study to investigate the effect of copper nanoparticles on the thermal conductivity of the nanofluid. Their results demonstrated that the suspended nanoparticles clearly enhanced the thermal conductivity of the base liquid. Furthermore, increasing the volume fraction of the nanoparticles leads to an increase of the thermal conductivity of the nanofluid.

Abu-Nada and Oztop [18] carried out a numerical investigation of a mixed convection in an inclined square cavity of an aluminium-based nanofluid. They concluded that convection heat transfer was significantly enhanced by the existence of different types of nanoparticles.

Tiwari and Das [19] confirmed that increasing the volume fraction of nanoparticles significantly enhances the convection heat transfer coefficient. They inspected the flow and heat transfer in a square enclosure utilizing the finite volume method by considering that the top and the bottom were insulated and the side walls remain at different constant temperatures. It is evident from the literature that the thermal conductivity of nanofluid highly depends on the volume fraction, the thermal conductivity (of both the base fluid and the nanoparticle material), the surface area, and the shape of the nanoparticles suspended in the base liquid.

There are few studies in the literature that investigated the effect of a nanofluid in forced convection. In contrast, a large number of studies were devoted to the effect of nanoparticle in the natural convection. The free convection in a rectangular cavity was numerically studied by Jang and Choi [19] and Jou and Tzeng [21]. They presented their numerical results of the heat transfer enhancement of nanofluid in a two-dimensional cavity. The influence of gravity on sedimentation and the agglomeration of nanoparticle on a natural convection heat transfer was investigated by Jafari et al. [22]. They proposed a single-phase approach and a mixture model. Ismail et al. [23] studied the buoyancy forces as the driving heat transfer of nanofluid, using FLUENT. The effect of particle sizes and shapes on the heat transfer characteristics and the pressure losses were studied by Meriläinen [24]. They determined that the average convective heat transfer coefficients of nanofluid were improved up to $40 \%$ compared to clear fluids. The mixed convection flow and the heat transfer analyses in a lid-driven inclined enclosure filled with a nanofluid were conducted by Iwatsu et al. [25]. The flow and the heat transfer in a square cavity with insulated top and bottom walls, and differentiallyheated moving sidewalls were also investigated using the finite volume approach by Mansour and Ahmed [26]. They investigated the effects of the Richardson number and the volume fraction of the nanoparticles on the heat transfer. It was observed that when the Richardson number equals unity, the average Nusselt number increased substantially with the increase in the volume fraction of the nanoparticles. The mixed convection flow in a lid-driven enclosure filled with a fluid-saturated porous medium was investigated by Abu-Nada and Chamakha [27]. They reported the effects of the Darcy and Richardson numbers on the flow and the heat transfer characteristics. A numerical study of laminar mixed convection in shallow driven cavities with a hot moving lid on top and cooled from the bottom has been carried out by Sharif [28]. It was observed that the average convection heat transfer increased slightly with the cavity inclination angle for the forced convection while it increased more significantly under natural convection.

Öztop et al. [29] investigated the heat transfer and the fluid flow due to buoyancy forces in a partially heated enclosure using different nanofluids. Calculations were performed for different Rayleigh numbers, heights of heater, locations of heater, aspect ratios, and volume fractions of nanoparticles. They found that the heat transfer increases with increases of the Rayleigh number, the height of heater and the volume fraction of nanoparticles. Furthermore, the heat transfer enhancement was found to be dependent on the type of nanofluid and more pronounced at lower aspect ratios.

Polidori et al. [30] utilized the integral formalism approach to investigate the natural convection heat transfer of a Newtonian nanofluid in a laminar external boundary-layer. They dealt with $\gamma-\mathrm{Al}_{2} \mathrm{O}_{3} /$ water nanofluid whose Newtonian behaviour was experimentally confirmed for particle volume fractions less than 0.04. They concluded that generalized conclusions about the heat transfer enhancement with the use of a nanofluid needs to be carefully drawn. In addition, they found that the natural convection heat 
transfer is not solely characterized by the nanofluid's effective thermal conductivity. Moreover, they concluded that the sensitivity to the used viscosity model cannot be ignored as it plays a key role in the heat transfer behaviour.

Putra et al. [31] executed an experimental work on the natural convection of $\mathrm{Al}_{2} \mathrm{O}_{3}$ and $\mathrm{CuO}$-water nanofluid inside a horizontal cylinder heated and cooled from both ends, respectively. They found that the presence of nanoparticles spoiled the natural convective heat transfer systematically. They also observed a systematic degradation of the natural convective heat transfer with increased concentrations of particles.

Haddad et al. [32] and [33] studied numerically the natural convection heat transfer and fluid flow of $\mathrm{CuO}$-water nanofluid in an open cavity heated from the bottom. They considered in their calculation the variation in the viscosity and the thermal conductivity. They found that the heat transfer decreases with increasing of solid volume fraction as a result of increasing the viscosity of the nanofluid.

Although many studies are found in the literature investigating the heat transfer characteristics of nanofluids, there is a lack of studies devoted to combined mixed convection flow and heat transfer. Moreover, due to nanofluid's superior thermophysical properties, utilizing nanofluids in industrial applications has recently witnessed rapid growth. However, there is still no accurate understanding of the effect of using nanoparticles in the combined convection heat transfer. Therefore, the main objective of this study is to investigate numerically the combined convection flow and heat transfer in a square lid-driven cavity utilizing nanofluid. General correlations for the effective thermal conductivity, the viscosity, and the thermal expansion coefficient of a nanofluid were adopted in this study in terms of the volume fraction, the particle diameter, the temperature, and the base fluid physical properties. These theoretical models were employed utilizing a user-defined function (UDF) in Fluent.

\section{MATHEMATICAL FORMULATION}

A steady, laminar, two-dimensional combined convective flow and heat transfer in a square lid-driven cavity filled with nanofluid is considered. The fluid in the cavity is water-based nanofluid containing $\mathrm{Al}_{2} \mathrm{O}_{3}$. The left and right walls of the cavity are insulated. The top wall is heated to temperature $T_{h}$ while the bottom wall is maintained at a temperature $T_{c}$ such that $T \mathrm{~h}>T_{c}$. The top wall of the cavity is allowed to move at a constant speed $U_{\infty}$. The physical model considered in this study is shown in Fig. 1. The shape and the size of particles are assumed to be uniform with diameter equal to $100 \mathrm{~nm}$. The fluid properties of the nanofluid vary when nanoparticles are suspended. In this study, the nanofluid is treated as a single phase. The thermophysical properties of the nanoparticles and the fluid phase at $T=300 \mathrm{~K}$ are presented in Table 1. Mixed convection flow and heat transfer in a square lid driven cavity are simulated by using the mass, momentum, and energy conservation equations. The governing non-linear partial differential equations can be written as follows:

$$
\begin{aligned}
& \frac{\partial U}{\partial X}+\frac{\partial V}{\partial Y}=0 \\
& U \frac{\partial U}{\partial X}+V \frac{\partial U}{\partial Y}=-\frac{\partial P}{\partial X}+\frac{1}{R e} \frac{\mu_{e f f}}{v_{f} \rho_{e f f}}\left[\frac{\partial^{2} U}{\partial X^{2}}+\frac{\partial^{2} U}{\partial Y^{2}}\right], \\
& U \frac{\partial V}{\partial X}+V \frac{\partial V}{\partial Y}=-\frac{\partial P}{\partial Y}+\frac{1}{R e} \frac{\mu_{e f f}}{\rho_{e f f}}\left[\frac{\partial^{2} V}{\partial X^{2}}+\frac{\partial^{2} V}{\partial Y^{2}}\right]+ \\
& +\frac{(\rho \beta)_{e f f}}{\rho_{\text {eff }}} \frac{G r}{\operatorname{Re}^{2}} \theta, \\
& U \frac{\partial U}{\partial X}+V \frac{\partial \theta}{\partial Y}=\frac{\alpha_{e f f}}{\alpha_{f}} \frac{1}{\operatorname{Pr} \operatorname{Re}}\left[\frac{\partial^{2} \theta}{\partial X^{2}}+\frac{\partial^{2} \theta}{\partial Y^{2}}\right] .
\end{aligned}
$$

The above equations were non-dimensionalized as follows:

$$
\begin{gathered}
U=\frac{u}{U_{\infty}}, \quad V=\frac{v}{U_{\infty}}, \quad X=\frac{x}{L}, \quad Y=\frac{y}{L}, \\
\theta=\frac{T-T_{c}}{T_{H}-T_{c}}, \quad P=\frac{p}{\rho_{e f f} U_{\infty}^{2}}, \\
R e=\frac{U_{\infty} L}{v_{f}}, \quad P r=\frac{v_{f}}{\alpha_{f}}, \\
G r=\frac{g \beta L^{3}\left(T_{H}-T_{c}\right)}{v^{2}}, \quad R i=\frac{G r}{R e^{2}},
\end{gathered}
$$

where $L$ is the reference length, $U_{\infty}$ is the reference velocity, and $v$ is the kinematic viscosity. The Reynold's number $R e$ is the ratio of inertial to viscous forces, which influences the fluid flow features within the cavity. The ratio of $G r / R e^{2}$ is the convection parameter and is called the Richardson number $R i$. It measures the relative strength of the natural convection and the forced convection for the present problem. 
Table 1. Thermophysical properties of the base fluid and aluminium [26]

\begin{tabular}{lcc}
\hline Physical properties & Water & $\mathrm{Al}_{2} \mathrm{O}_{3}$ \\
\hline$C_{p}[\mathrm{~J} /(\mathrm{kg} \cdot \mathrm{K})]$ & 4179 & 765 \\
\hline$k\left[\mathrm{~W} /\left(\mathrm{m}^{2} \cdot \mathrm{K}\right)\right]$ & 0.613 & 25 \\
\hline$\rho\left[\mathrm{kg} / \mathrm{m}^{3}\right]$ & 997.1 & 3970 \\
\hline$\mu[\mathrm{Pa} \cdot \mathrm{s}]$ & 0.000891 & - \\
\hline$\beta[1 / \mathrm{K}]$ & 0.00021 & 0.0000017 \\
\hline
\end{tabular}

\subsection{Boundary Conditions}

A schematic of the configuration analysed in this study is shown in Fig. 1. The appropriate dimensionless boundary conditions for the present study are as follows:

$$
\begin{gathered}
\frac{\partial \theta}{\partial Y}=0, \quad U=V=0, \quad X=0, \\
\frac{\partial \theta}{\partial Y}=0, \quad U=V=0, \quad X=1, \\
\theta=0, \quad U=V=0, \quad Y=0, \\
\theta=1, \quad U=1, \quad V=0, \quad Y=1 .
\end{gathered}
$$

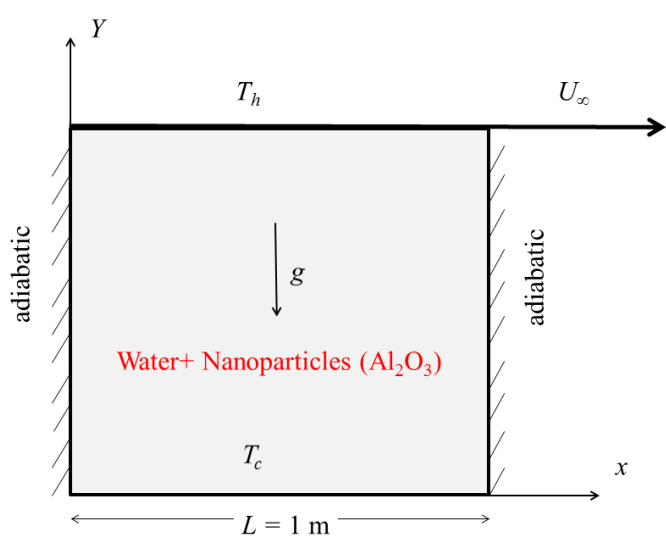

Fig. 1. Schematic of the square lid-driven cavity

\subsection{Thermo-Physical Properties of $A_{12} \mathrm{O}_{3}$-Water Nanofluid}

The nanofluid mixture is considered as a single phase; thus, the nanoparticles and the base fluid are in a thermal equilibrium with each other and the relative velocity is negligible or equal to zero. Therefore, the effective thermophysical properties that depend mainly on the temperature, volume concentration of the nanoparticles, and the properties of the base fluid and the suspended particles are adopted in this study. General correlations for the effective thermal conductivity, the viscosity, and thermal expansion coefficient of nanofluid were developed in terms of the solid volume fraction, the particle diameter, the temperature, and the base fluid physical properties, Kahnafer et al. [10]. These correlations have been implemented in Fluent using a user defined function.

\subsubsection{Density}

The density of nanofluid is based on the physical principle of the mixture rule [10].

$$
\rho_{\text {eff }}=\left(1-\varphi_{p}\right) \rho_{f}+\varphi_{p} \rho_{p},
$$

where $f$ and $p$ refer to the fluid and nanoparticle respectively, $\varphi_{p}$ is the solid volume fraction of the nanoparticles, and $\rho$ is the density.

\subsubsection{Viscosity}

Different models of viscosity have been used by researchers to model the effective viscosity of nanofluid as a function of solid volume fraction. For low solid volume fraction, Einstein's model can be used to predict the viscosity of the nanofluid.

It is worth mentioning that Einstein's model underestimates the nanofluid viscosity and does not consider the effect of temperature variations [34]. In this study, general correlation formulas to determine the effective viscosity of $\mathrm{Al}_{2} \mathrm{O}_{3}$-water considering the temperature effect proposed by Nguyen et al. [35] are used.

$$
\begin{gathered}
\mu_{e f f}=(1.125-0.0007 \times T) \mu_{f}, \\
\varphi_{p}=1 \%, \quad 20 \leq T\left[{ }^{\circ} \mathrm{C}\right] \leq 70, \\
\mu_{e f f}=\left(2.1275-0.0215 \times T+0.0002 \times T^{2}\right) \mu_{f}, \\
\varphi_{p}=4 \%, \quad 20 \leq T\left[{ }^{\circ} \mathrm{C}\right] \leq 70 .
\end{gathered}
$$

\subsubsection{Thermal Conductivity}

Numerous studies were conducted in the literature to model the thermal conductivity of nanofluid. A general thermal conductivity correlation for $\mathrm{Al}_{2} \mathrm{O}_{3}$ water nanofluid was proposed by Kahnafer et al. [10] for various temperatures, nanoparticles diameter, and solid volume fraction. The proposed correlation is given as follows:

$$
\begin{aligned}
\frac{k_{e f f}}{k_{f}}= & 1.0+1.0112 \varphi_{p}+ \\
& +2.4375 \varphi_{p}\left(\frac{47}{d_{p}(n m)}-0.0248 \varphi_{p}\left(\frac{k_{p}}{0.613}\right) .\right.
\end{aligned}
$$




\subsubsection{Thermal Expansion Coefficient}

The effect of temperature and solid volume fraction on the thermal expansion coefficient of $\mathrm{Al}_{2} \mathrm{O}_{3}$-water nanofluid were investigated by $\mathrm{Ho}$ et al. [36]. They developed a correlation for the thermal expansion coefficient of $\mathrm{Al}_{2} \mathrm{O}_{3}$ water nanofluid as a function of the temperature and the solid volume fraction of nanoparticles. This correlation is given as:

$$
\begin{gathered}
\beta_{\text {eff }}=\left(-0.479 \varphi_{p}+9.3158 \times 10^{-3} T-\frac{4.7211}{T^{2}}\right) \times 10^{-3} \\
0 \leq \varphi_{p} \leq 0.04, \quad 10 \leq T\left[{ }^{\circ} \mathrm{C}\right] \leq 40 .
\end{gathered}
$$

In this study, the values of the thermal expansion coefficient are evaluated utilizing Eq. (12) and based on the average temperature between cold and hot walls.

\subsubsection{Heat Capacity}

The specific heat of nanofluid is formulated by assuming a thermal equilibrium between the nanoparticles and the base fluid phase as follows [10]:

$$
c_{\text {eff }}=\frac{\left(1-\varphi_{p}\right) \rho_{f} c_{f}+\varphi_{p} \rho_{p} c_{p}}{\rho_{\text {eff }}},
$$

where $\rho_{p}$ is the density of the nanoparticle, $\rho_{f}$ is the density of the base fluid, $\rho_{\text {eff }}$ is the density of the nanofluid, and $c_{p}$ and $c_{f}$ are the heat capacity of the nanoparticle and the base fluid, respectively.

\section{NUMERICAL METHODS}

The finite volume method is employed using Fluent 6.3 commercial software to solve the governing equations subject to specified boundary conditions. Gambit commercial software is used for the generation of grids. A high number of cells are constructed near the surface of cavity walls to compensate for the high velocity gradient in the boundary layer region of the viscous flow. The coupling between the pressure and velocity fields is achieved using Simple scheme. A second order upwind scheme is used for the mixed convection. The coupled equations are solved sequentially. Time independent solver was used for all the simulation. Laminar model was used to simulate the mixed convection flow. A second order discretization scheme was used for all simulations. All the thermophysical properties material described above are implemented in the Fluent software using user defined function (UDF). The simulation is terminated when the residuals for continuity and momentum equations attain $10^{-6}$ and the residual for the energy equation attain $10^{-8}$. The local Nusselt number based on the length of the square cavity is expressed as:

$$
N u=-\left.\frac{k_{e f f}}{k_{f}} \frac{\partial \theta}{\partial Y}\right|_{Y=1} .
$$

The average Nusselt number of the hot wall can be obtained by integrating the local Nusselt number along the wall as:

$$
\overline{N u}=\int_{0}^{1} N u(X) d X
$$

\section{RESULTS AND DISCUSSION}

In order to ensure that computational results are gridindependent, different grid sizes were tested (see Table 2).

Table 2. Grid independence results for pure water $(\varphi=0)$

\begin{tabular}{lccc}
\hline Number of grids & $50 \times 50$ & $80 \times 80$ & $100 \times 100$ \\
\hline $\begin{array}{l}\text { Average Nusselt number at } \\
\text { the hot wall for } R i=0.1\end{array}$ & 7.0124 & 7.294 & 7.345 \\
\hline $\begin{array}{l}\text { Average Nusselt number at } \\
\text { the hot wall for } R i=1.0\end{array}$ & 2.2897 & 2.345 & 2.346 \\
\hline $\begin{array}{l}\text { Average Nusselt number at } \\
\text { the hot wall for } R i=10\end{array}$ & 1.653 & 1.671 & 1.677 \\
\hline
\end{tabular}

The grid independence tests are performed for pure water $(\varphi=0)$. Table 2 illustrates the results of independence studies for average Nusselt number $N u$ at the hot wall for different Richardson numbers, $R i$. From Table 2, it is noticeable that grid sizes of $80 \times 80$ and $100 \times 100$ give almost the same results for the average Nusselt number. For further validation, the present numerical solutions are validated against experimental as well as numerical results.

The numerical results are compared in terms of Nusselt number and $U$-velocity at the mid-section of the cavity and found to be in good agreement with previous works (see Figs. 2 and 3). It is worth mentioning that when $R i \rightarrow \infty$, the heat transfer by natural convection is dominant, while when $R i \rightarrow 0$ , the heat transfer by forced convection is dominant. In contrast, when $R i \rightarrow 1$, the heat transfer by the mixed convection is dominant. The Richardson number in this study varies from 0.1 to 10 . Numerical simulations are conducted to demonstrate the effects of Richardson number $R \mathrm{i}$ and solid volume fraction $\phi$ on mixed convection heat transfer in a square cavity. 
The value of the solid volume fraction varies from 0.0 to 0.04 . The local Nusselt number distributions along the hot moving wall for various Richardson numbers and solid volume fractions are illustrated in Figs. 4 and 5. The local Nusselt number is high near the left wall and decreases towards the right wall. The effect of the solid volume fraction and the Richardson number is clearly discernible in these figures.

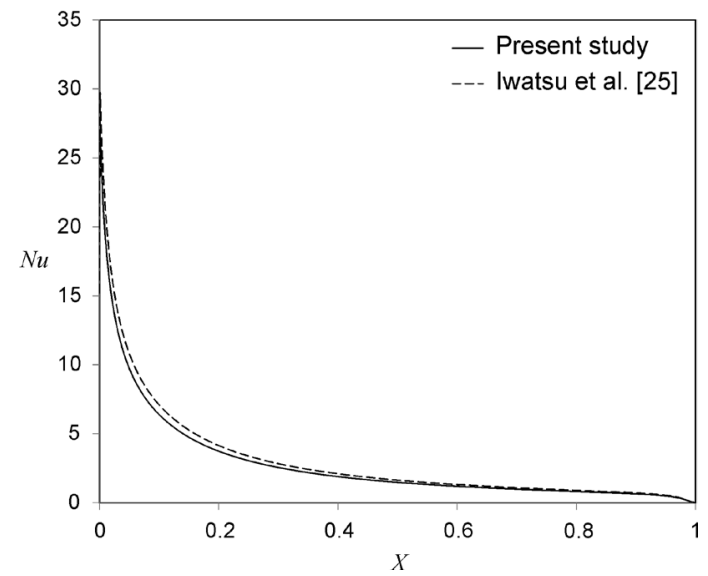

Fig. 2. Comparison of the local Nusselt number variation for hot wall for pure water and $R i=1$

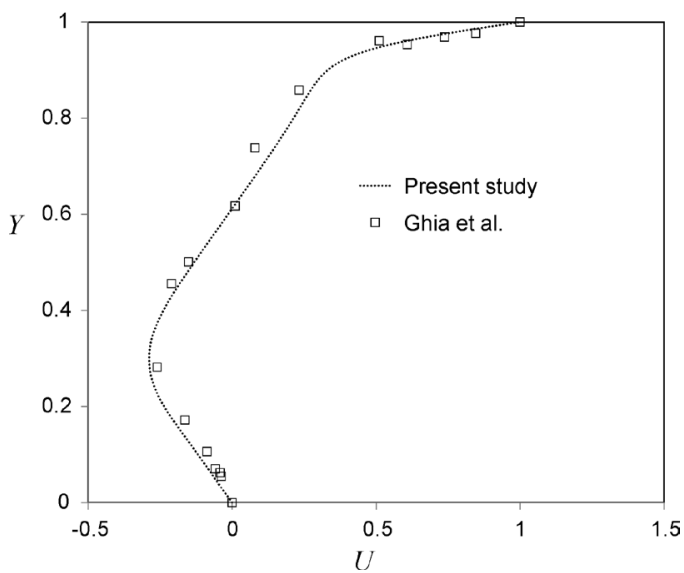

Fig. 3. Comparison of U-velocity at mid-section of the cavity $(X=0.5)$ for pure water and $R i=0.1$

In general, the local Nusselt number started to decrease sharply at the beginning (i.e. at the left wall) and then continues to decrease rapidly at the right wall. It is clear from these figures that for a laminar flow with a constant solid volume fraction, decreasing the Richardson number leads to a significant increase in the local Nusselt number. The reason for this enhancement is that the forced convection is becoming dominant when the Richardson number is low. It can be seen in Figs. 5a and $\mathrm{b}$ that the local Nusselt number increases as the solid volume fraction $\varphi$ increases for both $R i=10$ and $R i=1$. However, for $R i=0.1$ (see Fig. $5 c)$ the Nusselt number does not change significantly with the solid volume fraction.

The variations of the average Nusselt number with Richardson number along the hot wall for
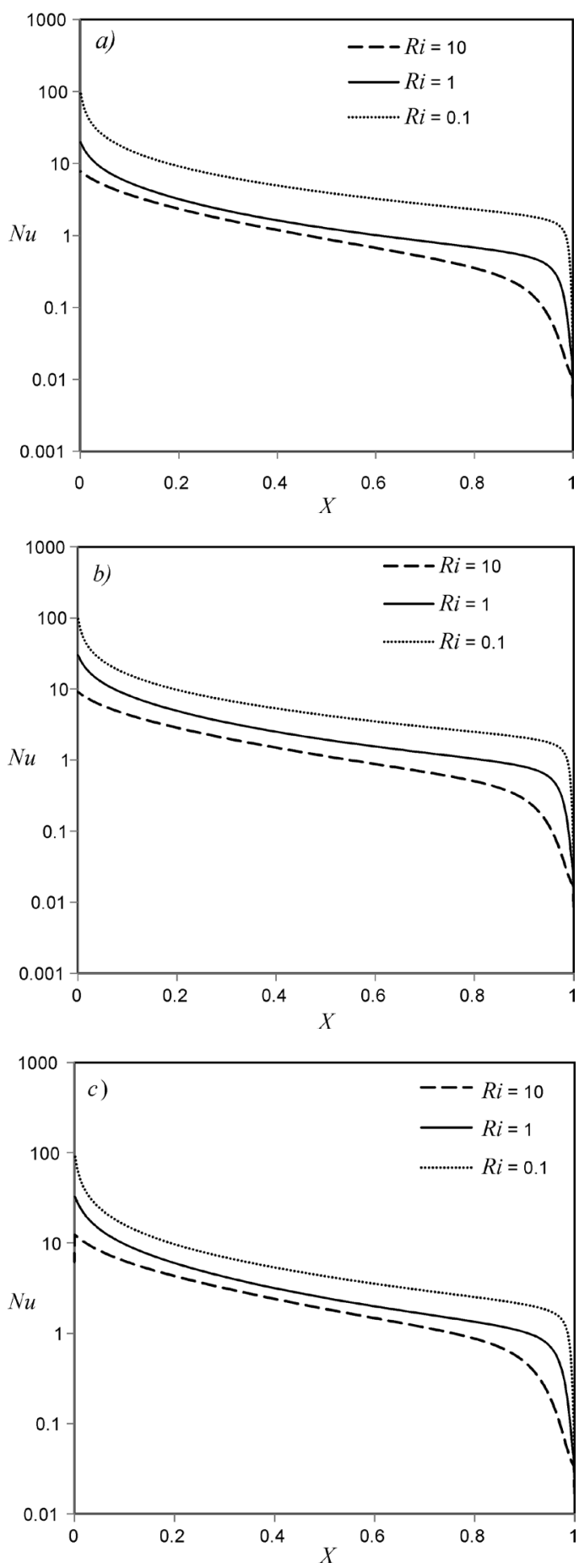

Fig. 4. Local Nusselt number for different solid volume fraction; a) $\varphi=0.0, b) \varphi=0.01$ and c) $\varphi=0.04$ 

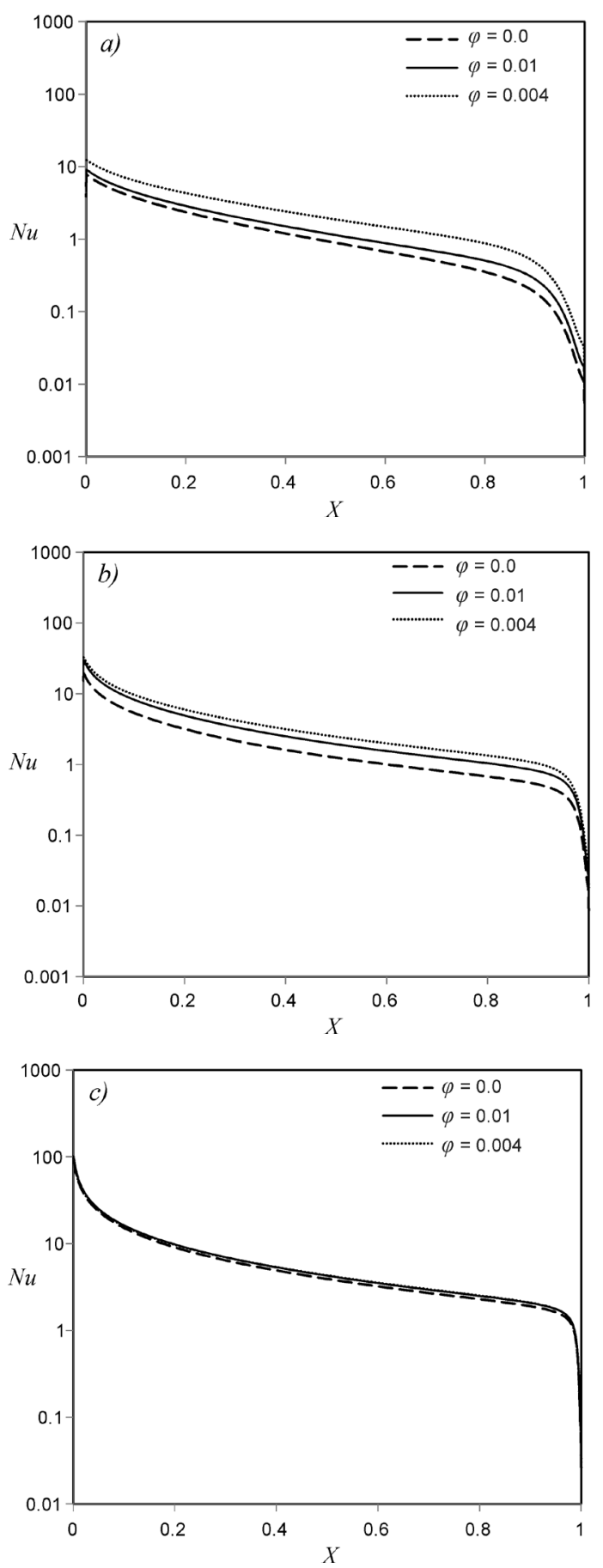

Fig. 5. Local Nusselt number for different Richardson number; a) $R i=10, b) R i=1$, and c) $R i=0.1$

different solid volume fractions are depicted in Fig. 6 . The figure shows that the average Nusselt number increases with the solid volume fraction and decrease with Richardson number.

Fig. 7 demonstrates the influence of the Richardson number on isotherms for the solid

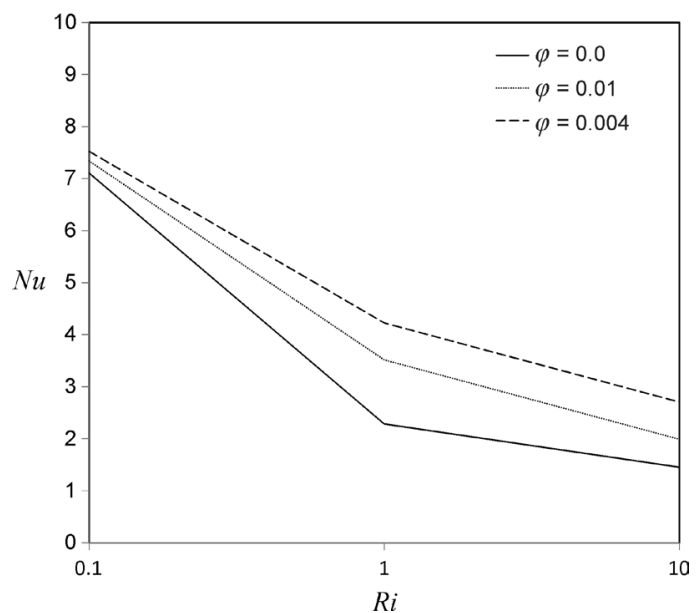

Fig. 6. Average Nusselt number verses Richardson number for different solid volume fraction

volume fraction $\varphi=0.04$. For $R i=0.1$, shear forces are dominant in the cavity and, thus, the isotherms are mostly congregated to the area near the bottom surface of the square cavity. The high temperature gradient near the bottom wall is due to these high shear forces developed due to movement of the cavity lid. Moreover, a thin boundary layer is developed on the top of the hot wall. Furthermore, a strong circulation region is observed in the centre of rotating vortex inside the cavity. Increasing $R i$ up to 1 , the shear forces and bouncy forces are the same magnitude, thus, coarse isotherms existed near the bottom wall. As a result, a moderate temperature gradient in the vertical direction can be seen. Further increases in Ri lead to wider expansion of isotherms covering the whole cavity. This leads to a further decrease of the heat transfer intensity near the bottom wall due to a stabilized free convection effect. It should be noted that for this case, the inertia force is weak. Therefore, the bouncy force defines the formed fluid flow and heat transfer inside the cavity.

Fig. 8 demonstrates the effect of a solid volume fraction on isotherms under the natural convection condition $(R i=10)$. For the case of pure water $(\varphi=0)$, most of the entire cavity is in a thermally stratified state. In other words, the isotherms are almost parallel in the horizontal direction, except for the isotherm area in the right upper corner, where the isotherms show significant changes. Increasing $\varphi$ up to 0.01 , the isotherm area in the right upper corner becomes bigger and the isotherms show significant changes. When the solid volume fraction is increased up to $\varphi=0.04$, the isotherms are clustered near the cold 
.

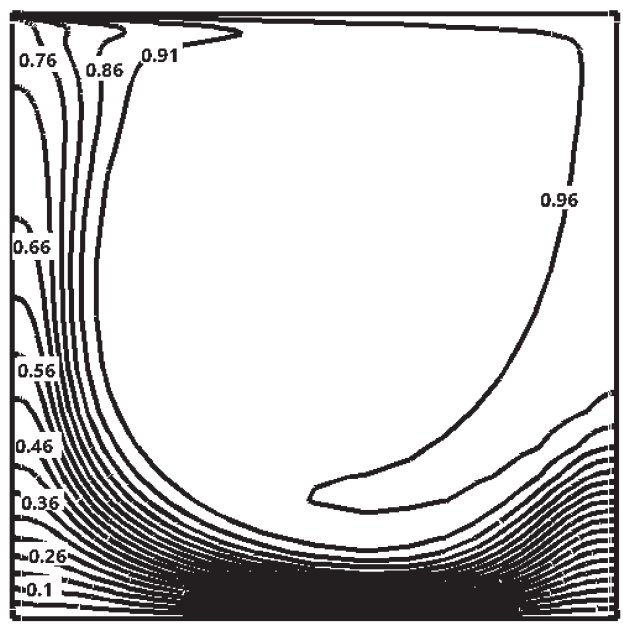

b)

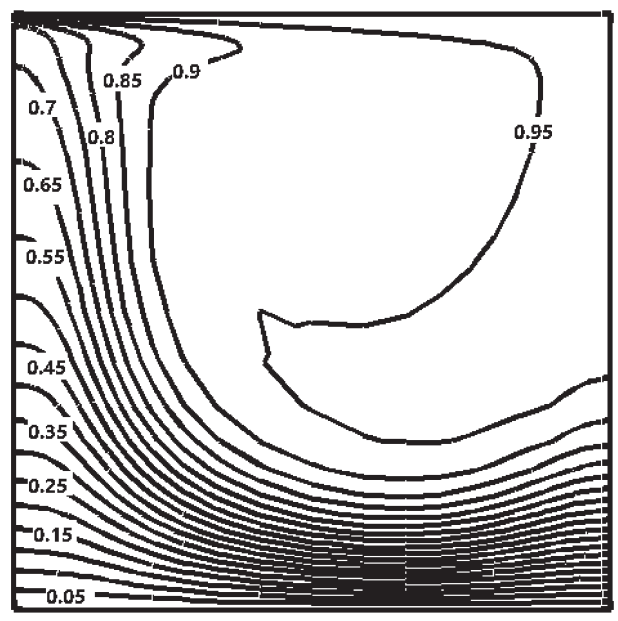

C)

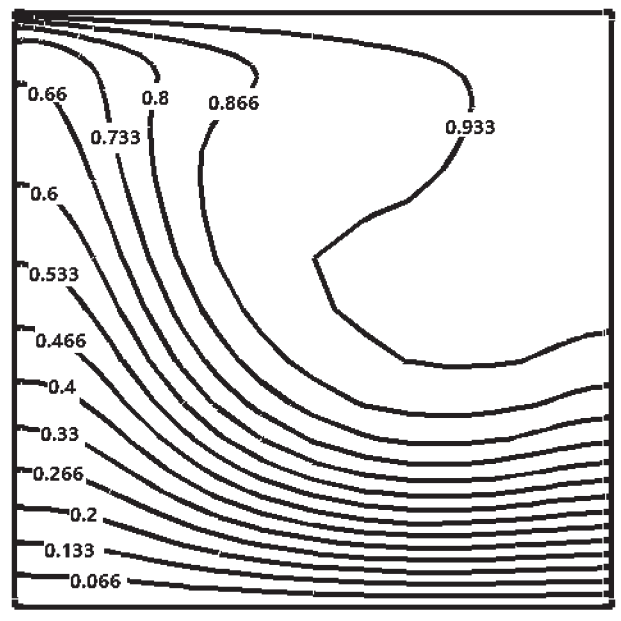

Fig. 7. Isotherm for different Richardson number, $\varphi=0.04$; a) $R i=0.1$, b) $R i=1$, and c) $R i=10$

bottom wall. These changes are due to a high temperature gradient near the bottom wall. These changes have led to the increased thermal conductivity of nanofluid.

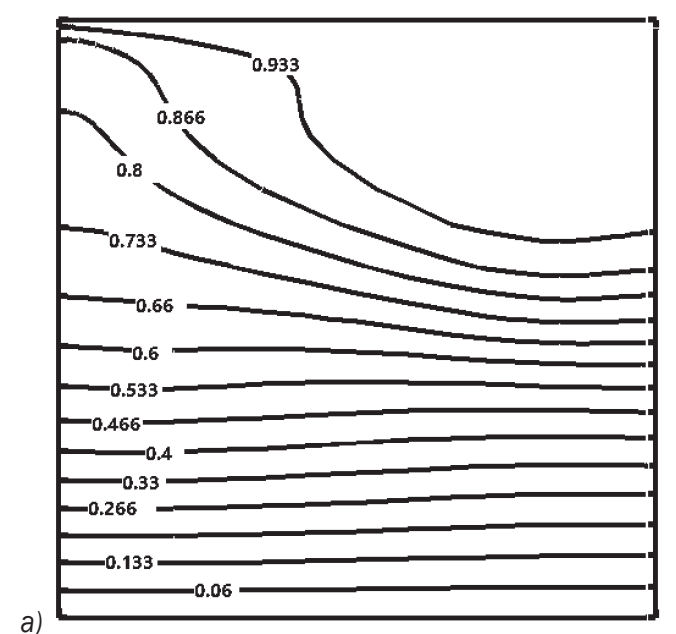

a)
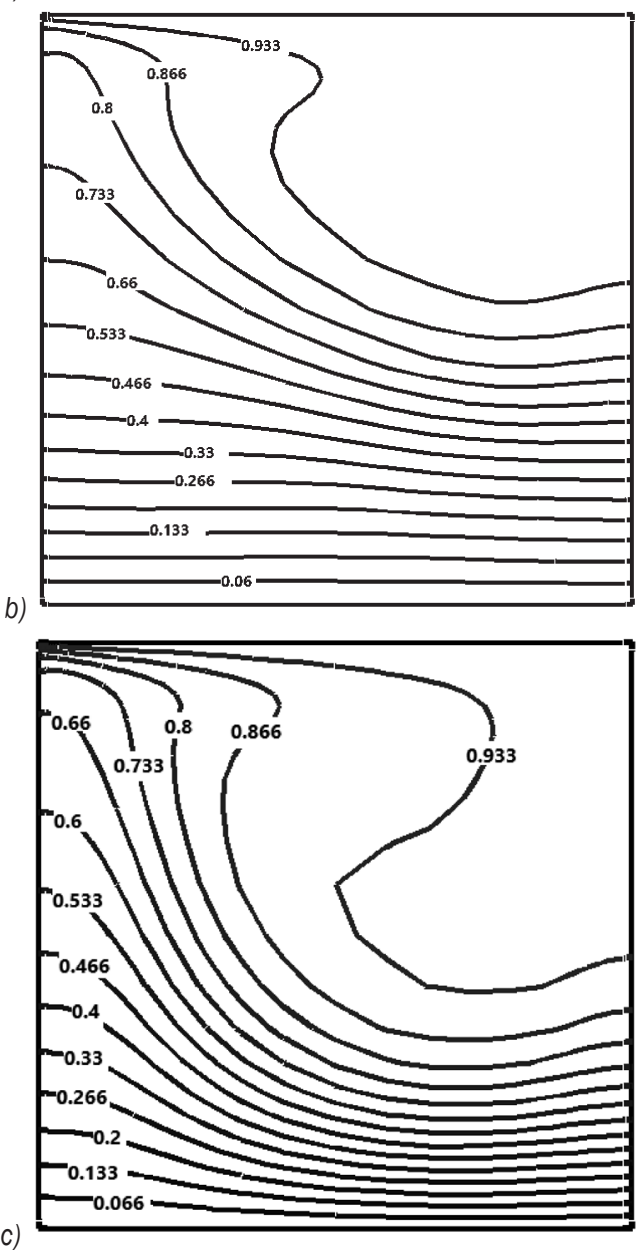

Fig. 8. Isotherm for different nanoparticle solid volume fraction, $R i=10$; a) $\varphi=0, b) \varphi=0.01$, and c) $\varphi=0.04$

Fig. 9 demonstrates the influence of solid volume fraction on streamlines for the free convection case $(R i=10)$. For $R i=10$, the bouncy force is dominant in the cavity and streamlines are mostly concentrated 


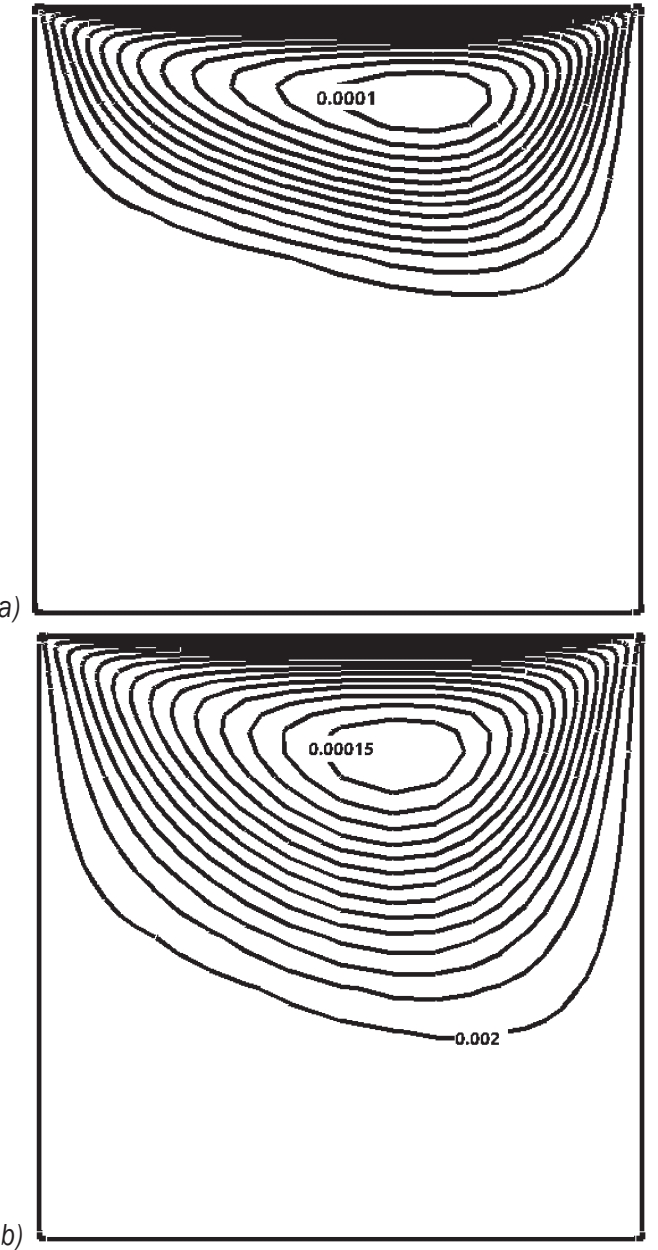

b)

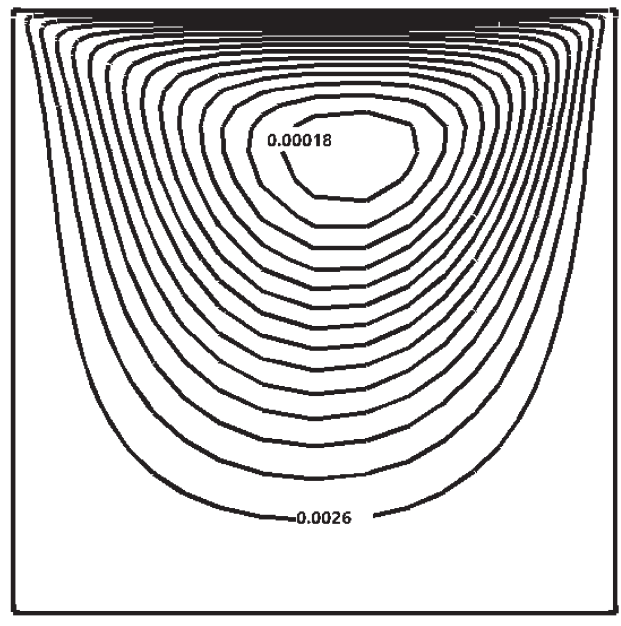

Fig. 9. Stream function for different nanoparticle solid volume fraction for $R i=10(\mathrm{~kg} / \mathrm{s}) ; a) \varphi=0, b) \varphi=0.01$, and c) $\varphi=0.04$

towards the top moving wall. Moreover, a denser distribution of streamlines near the top moving wall is observed for pure water $(\varphi=0)$. Further increase of $\phi$ leads to expansion of streamlines covering the whole cavity due to the free convection enhancement. When the solid volume fraction is increased to $\varphi=0.04$, flow circulation is slightly increased. This can be explained as follows: increasing the solid volume fraction leads to increasing the bouncy force, which ultimately enhances the thermal conductivity.

\section{CONCLUSIONS}

The utilization of nanofluid in industrial applications has recently witnessed rapid growth due to their superior thermophysical properties. There is a need for a deeper and an accurate understanding of the effect of using nanoparticles in the combined convection heat transfer. Thus, this study focuses on the numerical investigation of steady, laminar mixed convection flow, and heat transfer in a lid-driven square cavity filled with water- $\mathrm{Al}_{2} \mathrm{O}_{3}$ nanofluid. The CFD model that includes the temperature variation effects on the thermophysical properties is validated against experimental results and found to be in good agreement. It was found that the local Nusselt number at $R i=1$ is augmented considerably by increasing the solid volume fraction of nanoparticles. At a relatively lower Richardson number $(R i=0.1)$, the local Nusselt number does not change significantly with the presence of nanoparticles. It was concluded that when the solid volume fraction and Richardson number are varied, different typical patterns of isotherms are obtained. Furthermore, the streamline pattern in the square lid-driven cavity was almost completely described by primary recirculation, and there were no significant changes when solid volume fraction changes.

\section{REFERENCES}

[1] Cha, C.K, Jaluria, Y. (1984). Recirculation mixed convection flow for energy extraction. International Journal of Heat and Mass Transfer, vol. 27, no. 10, p. 1801-1810, DOI:10.1016/0017-9310(84)90162-5.

[2] Ghia, U., Ghia, K.N., Shin, C.T. (1982). High-Re solutions for incompressible flows using the Navier-Stokes equations and a multigrid method. Journal of Computational Physics, vol. 48, no. 3, p. 387-411, D0l:10.1016/0021-9991(82)90058-4.

[3] Senthilraja, S., Karthikeyan, M., Gangadevi, R., (2010). Nanofluid applications in future automobiles: comprehensive review of existing data. Nano-Micro Letters, vol. 2, no. 4, p. 306-310, DOI:10.1007/BF03353859.

[4] Imberger, J., Hamblin, P.F. (1982). Dynamics of lakes, reservoirs, and cooling ponds. Annual Review of Fluid Mechanics, vol. 14, p. 153-187, D0l:10.1146/annurev. fl.14.010182.001101. 
[5] Kumar, A., Vemula, P.K., Ajayan P.M., John, G. (2008) Silver-nanoparticle-embedded antimicrobial paints based on vegetable oil. Nature Materials, vol. 7, p. 236-241, DOI:10.1038/nmat2099.

[6] Choi, S.U.S. (1995). Development and applications of NonNewtonian flows. Singer, D.A., Wang, H.P. (eds.) Development and Application of non-Newtonian Flows, p. 99-105, ASME, New York.

[7] Vajjha, R.S., Das, D.K. (2012). A review and analysis on influence of temperature and concentration of nanofluid on thermophysical properties, heat transfer and pumping power. International Journal of Heat and Mass Transfer, vol. 55, no. 15-16, p. 4063-4078, D0l:10.1016/j. ijheatmasstransfer.2012.03.048.

[8] Khaled, A.-R.A., Vafai, K. (2005). Heat transfer enhancement through control of thermal dispersion effects. International Journal of Heat and Mass Transfer, vol. 48, no. 11, p. 21722185, D0I:10.1016/j.ijheatmasstransfer.2004.12.035.

[9] Torrance, K., Davis, R., Eike, K., Gill, P., Gutman, D., Hsui, A., Lyons, S., Zien, H. (1972). Cavity flows driven by buoyancy and shear. Journal of Fluid Mechanics, vol. 51, no. 2, p. 221-231, DOI:10.1017/S0022112072001181.

[10] Khanafer, K., Vafai, K., Lightstone, M. (2003). Buoyancy-driven heat transfer enhancement in a two-dimensional enclosure utilizing nanofluids. International Journal of Heat and Mass Transfer, vol. 46, no. 19, p. 3639-3653, D0l:10.1016/S00179310(03)00156-X.

[11] Jung, J.-Y., Cho, C., Lee, W.H., Kang, Y.T. (2011). Thermal conductivity measurement and characterization of binary nanofluids. International Journal of Heat and Mass Transfer, vol. 54, no. 9-10, p. 1728-1733, D0l:10.1016/j. ijheatmasstransfer.2011.01.021.

[12] Kang, H.U., Kim, S.H., Oh, J.M. (2006). Estimation of thermal conductivity of nanofluid using experimental effective particle volume. Experimental Heat Transfer, vol. 19, no. 3, p. 181191, D0I:10.1080/08916150600619281.

[13] Lee, S., Choi, S.U.-S., Eastman, J.A. (1999). Measuring thermal conductivity of fluids containing oxide nanoparticles. Journal of Heat Transfer, vol. 121, no. 2, p. 280-289, DOI:10.1115/1.2825978.

[14] Wang, X.-Q., Mujumdar, A.S. (2007). Heat transfer characteristics of nanofluids: a review. International Journal of Thermal Sciences, vol. 46, no. 1, p. 1-19, D0l:10.1016/j. ijthermalsci.2006.06.010.

[15] Pak, B.C., Cho, Y.I. (1998). Hydrodynamic and heat transfer study of dispersed fluids with submicron metallic oxide particles. Experimental Heat Transfer, vol. 11, no. 2, p. 151170, D0I:10.1080/08916159808946559.

[16] Xuan, Y., Li, Q. (2000). Heat transfer enhancement of nanofluids. International Journal of Heat and Fluid Flow, vol. 21, no. 1, p. 58-64, Dol:10.1016/S0142-727X(99)00067-3.

[17] Xuan, Y., Li, Q. (2003). Investigation on convective heat transfer and flow features of nanofluids. Journal of Heat Transfer, vol. 125, no. 1, p. 151-155, D0l:10.1115/1.1532008.

[18] Abu-Nada, E., Oztop, H.F. (2009). Effect of inclination angle on natural convection in enclosures filled with $\mathrm{Cu}$-water nanofluid. International Journal of Heat and Fluid Flow, vol. 30, no. 4, p. 669-678, D0I:10.1016/j.ijheatfluidflow.2009.02.001.
[19] Tiwari, R.K., Das, M.K. (2007). Heat transfer augmentation in a two-sided lid-driven differentially heated square cavity utilizing nanofluids. International Journal of Heat and Mass Transfer, vol. 50, no. 9-10, p. 2002-2018, D0l:10.1016/j. ijheatmasstransfer.2006.09.034.

[20] Jang, S.P., Choi, S.U.S. (2004). Free convection in a rectangular cavity (Benard convection) with nanofluids. Proceedings of International Mechanical Engineering Congress and Exposition, Anaheim, p. 147-153, Dol:10.1115/ IMECE2004-61054.

[21] Jou, R.-Y., Tzeng, S.-C. (2006). Numerical research of natural convective heat transfer enhancement filled with nanofluid in rectangular enclosures. International Communication of Heat and Mass Transfer, vol. 33, no. 6, p. 727-736, D0l:10.1016/j. icheatmasstransfer.2006.02.016.

[22] Jafari, A., Mousavi, S.M., Tynjala, T., Sarkomaa, P. (2009). CFD simulation of gravitational sedimentation and clustering effects on heat transfer of a nano-ferrofluid. PIERS Proceedings, p. 1352-1356.

[23] Ismail, A.F., Rashmi, W., Khalid, M. (2008). Numerical study on buoyancy driven heat transfer utilizing nanofluid in a rectangular enclosure. Proceedings of the UK-Malaysia Engineering Conference, p. 118-123.

[24] Meriläinen, A., Seppälä, A., Saari, K., Seitsonen, J., Ruokolainen, J., Puisto, S., Rostedt, N., Ala-Nissila, T. (2013). Influence of particle size and shape on turbulent heat transfer characteristics and pressure losses in water-based nanofluids. International Journal of Heat and Mass Transfer, vol. 61, p. 439-448, D0I:10.1016/j.ijheatmasstransfer.2013.02.032.

[25] Iwatsu, R., Hyun, J.M., Kuwahara, K. (1993). Mixed convection in a driven cavity with a stable vertical temperature gradien. International Journal of Heat and Mass Transfer, vol. 36, no. 6, p. 1601-1608, DOl:10.1016/S0017-9310(05)80069-9.

[26] Mansour, M.A., Ahmed, S.E. (2013). Mixed convection in double lid-driven enclosures filled with $\mathrm{Al}_{2} \mathrm{O}_{3}$-water nanofluid. Journal of Thermophysics and Heat Transfer, vol. 27, no. 4, p. 707-718, DOI:10.2514/1.T4102.

[27] Abu-Nada, E., Chamkha, A.J. (2010). Mixed convection flow in a lid-driven inclined square enclosure filled with a nanofluid. European Journal of Mechanics - B/Fluids, vol. 29, no. 6, p. 472-482, D0l:10.1016/j.euromechflu.2010.06.008.

[28] Sharif, M.A.R. (2007). Laminar mixed convection in shallow inclined driven cavities with hot moving lid on top and cooled from bottom. Applied Thermal Engineering, vol. 27, no. 5-6, p. 1036-1042, D0I:10.1016/j.applthermaleng.2006.07.035.

[29] Öztop, H.F., Estellé, P., Yan, W-M., Al-Salem, K., Orfi, J., Mahian, 0. (2015). A brief review of natural convection in enclosures under localized heating with and without nanofluids. International Communication in Heat and Mass Transfer, vol. 60, p. 37-44, D0I:10.1016/j.icheatmasstransfer.2014.11.001.

[30] Polidori, G., Fohanno, S., Nguyen, C.T. (2007). A note on heat transfer modeling of Newtonian nanofluid in laminar free convection. International Journal of Thermal Sciences, vol. 46, no. 8, p. 739-744, D0I:10.1016/j.ijthermalsci.2006.11.009.

[31] Putra, N., Roetzel, W., Das, S.K. (2003). Natural convection of nano-fluids. Heat and Mass Transfer, vol. 39, no. 8, p.775784, D0I:10.1007/s00231-002-0382-z. 
[32] Haddad, Z., Öztop, H.F., Abu-Nada, E., Mataoui, A. (2012). A review on natural convective heat transfer of nanofluids. Renewable and Sustainable Energy Reviews, vol. 16, no. 7, p. 5363-5378, D0l:10.1016/j.rser.2012.04.003.

[33] Haddad, Z., Abu-Nada, E., Öztop, H.F., Mataoui, A. (2012). Natural convection in nanofluids: Are the thermophoresis and Brownian motion effects significant in nanofluid heat transfer enhancement?, International Journal of Thermal Sciences, vol. 57, p. 152-162, D0l:10.1016/j.ijthermalsci.2012.01.016.

[34] Einstein, A. (1956). Investigation on the Theory of Brownian Movement. New York, Dover.
[35] Nguyen, C.T., Desgranges, F., Roy, G., Galanis, N., Maré, T. Boucher, S., Mintsa, H.A. (2007). Temperature and particlesize dependent viscosity data for water-based nanofluids - Hysteresis phenomenon. International Journal of Heat and Fluid Flow, vol. 28, no. 6, p. 1492-1506, D0l:10.1016/j. ijheatfluidflow.2007.02.004.

[36] Ho, C.J., Liu, W.K., Chang, Y.S., Lin, C.C. (2010). Natural convection heat transfer of alumina-water nanofluid in vertical square enclosure: An experimental study. International Journal of Thermal Sciences, vol. 49, no. 8, p. 1345-1353, DOI:10.1016/j.ijthermalsci.2010.02.013. 